\title{
Isolating SRP
}

T

ike a crate of beer ready to be shipped overseas, secretory proteins carry a label that says, "For Export." With clever experiments, Günter Blobel of Rockefeller University and his post-doc Bernhard Dobberstein (Blobel and Dobberstein, 1975a,b) showed that the cell's export label is the signal sequence, a short stretch of amino acids that guides the forming protein to the ER (see "Lost in translation: the signal hypothesis" JCB 170 : 338). But the group still didn't know how the emerging protein recognized the ER or traversed the membrane, or what enzyme clipped off the signal sequence. When Dobberstein started his own lab at the European Molecular Biology Laboratory in Heidelberg, Germany, two teams began vying to solve these questions, lobbing papers across the Atlantic. "It was highly competitive, but it was friendly," Dobberstein recalls. Peter Walter, who was then Blobel's new graduate student and is now a cell biologist at the University of California, San Francisco, calls this period the best time in his life.

To flush out proteins responsible for this process of "translocation," Dobberstein and colleague Graham Warren washed microsomes with potassium chloride. The solution swept away the microsomes' ability to take in and process proteins (Warren and Dobberstein, 1978), but recombining microsomes with the salty extract repaired the system.

These treatments removed from the microsomes a cluster of six proteins (Walter and Blobel, 1980). A series of studies confirmed that this signal recognition protein, or SRP, was the "binding factor" that, according to Blobel and Sabatini's hypothesis, escorts an elongating protein to the ER membrane. The first of a trio of papers (Walter et al., 1981) suggested that SRP recognizes the signal sequence. The protein complex stuck to ribosomes making the secretory protein preprolactin, but not to ribosomes making the nonsecreted globin. What's more, SRP curbed translation of preprolactin.

During synthesis of preprolactin, translation halted after $\sim 70$ amino acids had linked up (Walter and Blobel, 1981b). Because 40 of these amino acids would still be buried in the ribosome, SRP must be glomming onto the remaining 30this estimate matched the lab's previous measurements of the signal sequence's length. Walter and Blobel (1981a) also showed that ribosomes couldn't bind to microsomes bathed in a salt solution. Adding SRP allowed the ribosomes to hook on and make the processed form of preprolactin, establishing that the complex was crucial for translocation and completion of secretory proteins.

Then a fluke event revealed an overlooked part of SRP. Walter was using a spectrophotometer to check purified SRP samples, and another person in the lab had left the machine at 254 nanometers, the absorbance peak for nucleic acids. To Walter's surprise, the SRP also absorbed at that wavelength. The signal recognition "protein," he discovered, sported RNAand it needed a new name. The researchers settled on "signal recognition particle," preserving the abbreviation. That was a good choice, Walter says, because "I didn't have to remake all my slides."

But SRP couldn't do it alone. A mystery protein, hints of which had been seen in the Blobel and Dobberstein labs (Meyer and Dobberstein, 1980a,b; Meyer et al., 1982), turned out to be the SRP receptor (Gilmore et al., 1982a,b). It juts from the ER membrane and serves as a landing pad for the SRP-ribosome conglomeration.

When Blobel's grad student Emily Evans purified the signal peptidase that chops out the signal sequence (Evans et al., 1986), only one big question remained: how do proteins cross the membrane? Early on, Blobel and Dobberstein (1975a) had hypothesized that a protein channel spanning the membrane opened to admit the strand and then closed. "That got me into tremendous problems," Blobel says. Critics pronounced such a channel unnecessary and argued that the membrane was thermodynamically competent to import the protein without it. However, yeast mutants that couldn't import proteins into the ER (Deshaies and Schekman, 1987) cast doubt on the membrane idea, and Blobel and his postdoc Sanford Simon were able to measure the electrical conductance of individual protein channels (Simon and Blobel, 1991). Blobel points out that the discovery

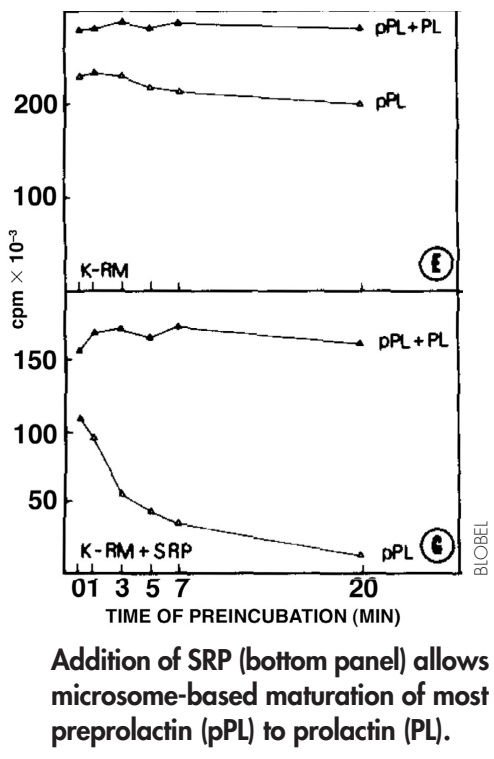

of the translocation system relied mainly on standard cell biology techniques rather than gene knockouts. Walter adds that these "old-fashioned" procedures were crucial, providing information that made later genetic results intelligible. "I would do it the same way again," he says. ML

Blobel, G., and B. Dobberstein. 1975a. J. Cell Biol. 67:835-851.

Blobel, G., and B. Dobberstein. 1975b.

J. Cell Biol. 67:852-862.

Deshaies, R.J., and R. Schekman. 1987.

J. Cell Biol. 105:633-645.

Evans, E., et al. 1986. Proc. Natl. Acad.

Sci. USA. 83:581-585.

Gilmore, R., et al. 1982a. J. Cell Biol.

95:463-469.

Gilmore, R., et al. 1982b. J. Cell Biol.

95:470-477.

Meyer, D.I., and B. Dobberstein. 1980a.

J. Cell Biol. 87:498-502.

Meyer, D.I., and B. Dobberstein. 1980b.

J. Cell Biol. 87:503-508.

Meyer, D.I., et al. 1982. Nature.

297:647-650.

Simon, S.M., and G. Blobel. 1991. Cell.

65:371-380.

Walter, P., and G. Blobel. 1980. Proc. Natl.

Acad. Sci. USA. 77:7112-7116.

Walter, P., and G. Blobel. 1982. Nature. 299:691-698.

Walter, P., and G. Blobel. 1981 a.

J. Cell Biol. 91:551-556.

Walter, P., and G. Blobel. $1981 \mathrm{~b}$.

J. Cell Biol. 91:557-561.

Walter, P., et al. 1981. J. Cell Biol.

91:545-550.

Warren, G., and B. Dobberstein. 1978.

Nature.:569-571. 